\title{
SOME CURRENT PROBLEMS IN SECOND-LANGUAGE TEACHING
}

\author{
Ronald Wardhaugh \\ University of Michigan
}

THAT EVERY language is systematic and that a second language should be learned as a habit system appear to have been two fundamental concepts acquired by language teachers trained in those schools which favor the so-called "linguistic method" of secondlanguage teaching. While there is no question that these two concepts have much to recommend them and that those teachers who have based their methodology on the concepts have achieved considerable success, yet neither concept is completely adequate nor do both together form a sufficient basis for a complete second-language pedagogy. A language is more than a system of habits, for a native speaker has abilities beyond those which can be accounted for under most existing definitions of habit, for example abilities to make judgments about such matters as grammaticality, foreign accent, deviancy, synonymy and paraphrase. This is not to say that habit formation drill has outlived its usefulness. Such drill can indeed teach control of the necessary surface skills in a second language, but it is the acquisition of abilities such as those mentioned above which marks off a person thoroughly competent in a new language from a person with limited skills, and the development of such abilities requires more than the use of existing stimulus-response or reinforcement drills in the classroom. Such drills are a necessary part of a good second-language teaching program; they are not, however, sufficient by themselves.

No long search is necessary to find language defined as some kind of habit system, for an examination of almost any introductory linguistics text will produce a definition of language which relies on such terms as arbitrary and system, and any discussion of these terms is almost sure to make the point that a native speaker of any language uses the arbitrary system of that language unthinkingly and habitually. Texts on language teaching likewise include statements that the teacher of a second language is to consider his task to be one of building a new habit system on top of or alongside an old system. Nelson Brooks, for example, points out: "The single paramount fact about language learning is that it concerns, not problem solving, but the formation and performance of habits. "I In Language

1 Nelson Brooks, Language and Language Learning (New York: Harcourt, Brace \& World, 1964), p. 49. 
Teaching: A Scientific Approach, ${ }^{2}$ Robert Lado concludes the fourth chapter, entitled "A Modern Theory of Language Learning," with a presentation of certain extremely behavioristic laws of language learning which, he claims, "although based on experience and inferences from learning research, are nevertheless entirely hypothetical." 3 The actual presentation of the laws and the theory said to underlie the laws, however, would indicate that Lado considers them to be fairly well validated in general principle if not in complete detail.

It is not really surprising that such an orientation can be found among many linguists and language teachers. Statements that languages are systematic, that meaning is conveyed through structure, and that although language systems differ from each other yet they may be described by following a certain set of procedures which make use of one or another set of analytical techniques have been made frequently by linguists. That these statements have been made during a period of time in which psychologists were concerned with stimulus-response and reinforcement theories was also a happy coincidence. Furthermore, when the revolution in technology produced the electronic gadgetry we have come to know, if not always to have, or even to use skillfully if we do have it, still a further im petus was given to teaching second languages as habit systems.

In all of this activity there has been a tendency to overlook two important facts about language. The first is that although certain structural and lexical characteristics of language use may be mechanical and important for that reason, those which are voluntary create many interesting linguistic and pedagogic problems which remain largely unsolved. The second is that while habit formation theory has been formulated from observations of either certain characteristics of the behavior of pigeons, rats and other nonhumans or certain aspects of the non-linguistic behavior of humans, language is essentially a human possession, possibly differing in kind rather than in degree from any other type of animal or human behavior. In a recent review of Lado's book, Sol Saporta has commented as follows on the notions that he perceives to be behind the "linguistic method": "These notions do not follow directly from any theory of linguistic structure and probably not from any but the most superficial learning theory." 4 Superficial is certainly not too strong

\footnotetext{
2Robert Lado, Language Teaching: A Scientific Approacb (New York: McGraw-Hill, Inc., 1964).

3lbid., p. 44.

4Sol Saporta, Review of Robert Lado, Language Teaching: A Scientific Approach, Language, 41 (1965), p. 548.
} 
a word to describe many of the explanations and theorizings in the psychological literature on the subject of language learning, particularly if we remember that language is a unique activity and uniquely human.

The foregoing comments should not be taken as a denial that many useful contributions to linguistic research and language teaching have been made by those linguists, psychologists, and teachers who have stressed the habitual aspects of language function. The contributions have been both many and useful and there now exist some very valuable contrastive studies of phonology and syntax, clear statements concerning the similarities and differences between speech and writing, well thought-out attempts at gradation of learning experiences, and courses which emphasize teaching the language in question rather than teaching about that language. At the same time we must not forget that although many good introductory courses have been produced, some basic problems still remain.

There is, for example, a group of problems associated with motivational and personality variables in second-language learning, problems which need linguistic attention, but which more than that need the attention of psychologists and pedagogues, and perhaps of sociologists and anthropologists. A growing body of evidence points to the fact that student motivation is essential to almost any learning task and that drill may be quite ineffective unless it is perceived to have some almost immediate practical benefit. Except in the very early stages of second-language learning the amount of drill required by some teaching techniques and the amount of skill acquired are often perceived by students to be almost totally unrelated. However, motivation in second-language learning encompasses many other factors too: the purpose of the learning; the particular dialect of the language involved; and the total social and academic climate of the learning experience. Personality variables are closely related to motivational ones: degree of inhibition; possible feelings of inadequacy, rivalry or threat; anomie; preferred sense use in learning, for example visual rather than auditory; and many other variables related to sociocultural factors in the make-up of individual students.

An equally important group of problems and one much more amenable than the first group to investigation by linguists is that which centers on the problems associated with language description and language contrast. Most contrastive analyses, for example, are designed to reveal different surface contrasts between the first language and the second language and most methodology is designed to drill the correct surface representations of the second language. 
Analyses and drills focus in turn on phonology, grammar and lexicon, and the goal throughout is that the learning will be open-ended, so that there will be generalization, or, in Pike's terms, "nucleation."5 However, the highly structured materials of many current courses deliberately leave little or no scope for creativity in the early stages and are often quite inexplicit in the later stages as to the extent to which analogy and generalization offer appropriate means for productivity. The terms analogy and generalization themselves are ill-defined and cloud rather than clarify the issues which are involved.

Recent developments in grammatical theory seem to promise some help in coming to a better understanding of such notions as contrast between languages and productivity. These developments have clarified the distinction between the deep and surface structures of sentences so that it should now be possible to add a significant new dimension to contrastive analyses. Likewisè, the idea of productivity can be clearly related to a theory of language which maintains that a grammar is a finite set of rules which can be used to produce an infinite set of sentences. Moreover, the set of rules for any language has certain properties in common with the set of rules for any other language so that there are important linguistic universals among all languages. More and more persons concerned with second-language teaching are now seeking for opportunities to make use of these developments and insights in their work.

Certain basic changes appear to be necessary in making contrastive analyses so that such studies no longer refer entirely to surface contrasts. In order to understand a sentence in any language a listener must not only recognize the surface characteristics of that sentence but he must also assign that sentence a deep structure. In other words until a listener to a second language is aware of the deep elements and relationships of an utterance in the second language, he cannot fully comprehend it. It is apparent that surface similarities of sentences often conceal deep differences, as in an interesting book and a falling book or a spring sale and a fire sale. If asked to do so, a native speaker of English can detect ambiguities in a spring sale and a fire sale and this ability testifies to the fact that the utterances are capable of more than a single deep reading each; however, an analys is concerned entirely with surface representations will not explain the ambiguities and, therefore, cannot hope to explain the native speaker's reaction, when pressed, that these are indeed ambiguous utterances.

Contrastive studies which deal with both deep structures and

5K. L. Pike, "Nucleation," The Modern Language Journal, 44 (1960), pp. $291-5$. 
surface representations may result in courses which show a significant advance in the gradation of materials, even though at the moment there exist only fragmentary proposals as to how this might be done. ${ }^{6}$ It is to be hoped that such materials will also relate patterns in such a way that deep relationships will be established in the learners for patterns which would otherwise be left unrelated and that accidental surface correspondences will be treated separately and apart from each other so as to avoid unnecessary confusion and the possibility of serious error.

Perhaps too, deep analyses of languages will show significant similarities among languages. Some recent work suggests that this might be the case. 7 For example, Bach has attempted to show similarities in the embedded relative clauses, or "de-sentential modifiers," of English, German, Japanese and Swahili. He says: "Various unrelated and related languages seem to exhibit the same component transformations. The differences appear in the particular selections made, in the obligatory or optional character of the transformations and in further special rules..." $\mathrm{A}$ note of caution is sounded by Fillmore in a discussion of the possibility of going from one language to another by attempting to find equivalent deep structures. He concludes an article devoted to this problem by noting that "deep-seated systematic differences abound."9 If such is the case, the search for grammatical equivalences of this kind may have to be abandoned in favor of some kind of paraphrase equivalence.

Recent insights into the nature of language may also be useful in coming to an understanding of what exactly is involved in analogy, generalization and nucleation, that is the general problems of productivity and competence. Whenever a student of a second language creates an utterance in the second language he reveals something about his competence (or his lack of competence). The same is true whenever he is required to respond to a novel utterance. Unfortunately, however, it is difficult after the very early stages of learning to decide exactly which utterances are novel 10 and to distinguish

6W. O. Dingwall, "Transformational Generative Grammar and Contrastive Analysis," Language Learning, 14 (1964), pp. 147-60.

7Emmon Bach, "On Some Recurrent Types of Transformations," Report of the Sixteenth Round Table Meeting on Linguistics and Language Studies, C. W. Kreidler, editor(Washington, D. C.: Georgetown University Press, 1965), pp. 3-18.

8 Ibid., p. 17.

9C. J. Fillmore, "On the Notion 'Equivalent Sentence Structure'," POLA Report \#11 (Columbus: The Ohio State University, 1965), p. 128.

10 However, just as in first-language teaching, it seems best to assume that every utterance is a novel utterance almost right from the beginning of the language learning process. 
actual competence, the covert ability, from performance, the overt behavior. Again though there is some indication that it may be possible to begin to estimate students ' competence, that is their intuitive grasp of the language, through testing procedures which make use of ambiguities, nonsense elements and deviancies of various kinds. It is obvious that for one to be an accomplished speaker of a second language he must have acquired the same skills and abilities as a native speaker of that language. Therefore, like the native speaker he should be able to make linguistic judgments as well as be phonologically accurate. Teaching which makes use of the insights gained from study of deep structures may well result in students acquiring both phonological accuracy and the other abilities which characterize native-like grammatical control and competency.

Whether or not actual teaching materials should be ordered according to the ordering principles derived from a transformational grammar is still problematic. Likewise, still problematic is whether or not students of a second language should be taught about the language as well as taught the language. At least one recent report suggests that teaching about transformational grammar leads to the production of well-formed novel sentences by second-language learners. ${ }^{11}$ Requiring students to make grammatical transformations is obviously a very useful teaching procedure and one that has been used frequently. Using a course based on a transformational grammar is quite a different matter, and making students conscious of the principles of that grammar is far different again. Even if one has doubts about either (or both) of the latter uses of transformational grammar in second-language teaching, he should still agree that any insights that transformational grammar has to offer in contrastive analysis should be used. Also, there can be little doubt that fresh directions have to be found in the gradation of materials and in productivity. Perhaps in these problem areas too transformational grammar may open the doors to new advances.

$11 \mathrm{~J}$. W. Ney, "Transformational Grammar in a Ryudai Classroom," Language Learning, 15 (1965), pp. 51-60. 